\title{
METODOLOGIA EMPREGADA PARA O ENSINO DE SANEAMENTO, AOS ALUNOS DA "ESCOLA DE ENFERMAGEM DE RIBEIRÃO PRETO" "AVALIAÇÃO DO MÉTODO PELOS ALUNOS"
}

\author{
Daisy Leslie Steagall Gomes *
}

\section{I - INTRODUÇÃO}

Preparar enfermeiros que satisfaçam, em qualidade e quantidacie. aos programas de saúde do país, de forma dinâmica e com base nos fatores sócio-cultural-econômico-sanitários, tem sido nossa preocupação ao montarmos um programa de ensino. -

Na montagem do programa de Saneamento I, que é ministrado no primeiro ano básico do Curso de Graduação em Enfermagem, Escola de Enfermagem de Ribeirão Preto - Universidade de São Paulo. (EERP-USP), procuramos aplicar uma metodologia que permitisse ao aluno aquisição de conhecimentos, hábitos e atitudes dentro dos objetivos traçados, proporcionando-lhes ainda a saída das salas de aula, para irem à comunidade e suas Instituições, observando e anotando condições ligadas às teorias estudadas, e, ao mesmo tempo, integrando e relacionando conhecimentos adquiridos em outras disciplinas. Para isto, entramos em entendimentos com os professores responsáveis pelas disciplinas de Parasitologia, Estatística e Sociologia, procurando dentro das possibilidades uma integração de conhecimentos, uma vez que estas disciplinas são pararelas.**

Uma programação, nesta linha, pareceu-nos boa, mas os nossos alunos o que pensaram? Como se sentiram e como receberam a ex-

* Professor Colaborador do Departamento de Enfermagem Geral e Especializada junto à disciplina de Enfermagem de Saúde Pública da EERP-USP de Ribeirão Preto.

* Por "disciplina pararela", entende-se aquela que o aluno deve cursar concomitantemente com outra, fazendo-se, em separado, a avaliação do aprendizado (Regimento Geral da USP, artigo $96 \quad \S \quad 2 .^{\circ}$ ). 
periência? Quais as opiniões e comentários que gostaria de dar e fazer sobre a metodologia? Que fatores interferiram neste tipo de aprendizagem? Valeu a pena a experiência? Qual o saldo positivo?

Aplicar lim método de ensino e obter dos alunos as respostas das perguntas acima foi nossa finalidade nesta programação.

A disciplina de saneamento da EERP é de responsabilidade do Departamento de Enfermagem Geral e Especializada, coordenado e ministrado por uma enfermeira de saúde pública. No ano de 1971, a. carga horária foi de 75 horas; sendo 45 horas teóricas e 3.0 horas ie práticas, com 5 critérios, para 33 alunos, matriculados no primeiro ano de graduação em enfermagem. A disciplina teve a duração de 15 semanas, com 5 horas semanais, distribuídas em dois cias da semana.

\section{II - METODOLOGIA USADA NA DISCIPLINA DE SANEAMENTO}

Após a enumeração dos objetivos, elaboração do conteúdo, seleção dos critérios de avaliação, distribuição do programa, seu respectivo croncgrama, feita a escolha do método, tivemos a sequência:

\section{Parte Teórica}

a) Reunião com todos os alunos e a enfermeira responsável pela disciplina para expor-lhes o desenvolvimento do curso e a distribuição do programa que continha: os assuntos e seus tópicos; biblicgrafia correspondente; recursos audio-visuais disponíveis na Escola e visitas a serem feitas na comunidade.

Nesse programa, já estavam previstos os dias, locais e horas para: estudo em grupos; visitas à comunidade; apresentação do trabalho sob forma de simpósio; a provas final, e os critérios de avaliação.

b) Realização de um painel: "Saneamento e ligações com Enfer magem de Saúde Pública, Estatística, Parasitologia e Sociologia”, com a participação dos professores responsáveis pelas respectivas disciplinas.

c) Montagem dos Grupos de Estudo, feita por sorteio, num total de 7 (sete), para o desenvolvimento da parte teórica. Cada GE* escolhida o seu coordenador e passava a trabalhar de acordo com o roteiro e guia, recebidos no assunto que lhe fora atribuído (também por sorteio), sob a coordenação e supervisão da professora. Os alunos foram autorizados a mudar a ordem, sequência ou o próprio conteúdo ciesde que não fugissem aos objetivos propostos.

- GE - Grupo de Estudos. 
d) As atividades na comunidade foram feitas obedecendo a um horário flexível, uma vez que certas instituições estipulam um horário especial para isto. Os alunos levavam um ofício da EERPUSP, solicitando que fossem atendidos. Essas visitas eram relacionadas ao assunto que estava sendo estudado pelo grupo. Por exemplo o grupo responsável pelo "saneamento dos alimentos" visitou: mercado municipal, um super-mercado, um frigorífico, uma fábrica de bebidas, uma laticínio e a seção de saneamento do Centro de Saúcis local. Os alunos tinham liberdade de solicitar outras visitas que achassem convenientes.

e) As apresentações dos GE obedecem às datas e horários marcados previamente.

Os simpósios foram realizados pelos alunos, que usaram a exposição, demonstração e recursos audio-visuais (filmes, diapositivos, cartazes, jornais, fotografias, material trazido das visitas, etc.) . Apresentaram o assunto estudados e descreveram as visitas.

Nesse mesmo dia, foram entregues os relatórios por escrito do €studado e das visitas feitas.

No final, a classe fez perguntas, pediu esclarecimentos e alguns foram escolhidos para uma crítica suscinta sobre a apresentação.

A professora fez complementaçōes, quando necessárias, a avaliação sobre o simpósio e o trabalho de cada grupo.

Esta programação proposta para a parte teórica foi toda executada dentro do tempo previsto.

2. Parte Prática

Na apresentação do último simpósio, foi pedido que cada grupo trouxesse, para a aula seguinte, um plano esquemático para a realização do trabalho prático, com base nos estudos feitos.

Reunidos os 7 (sete) GE, cada um expôs a linha de trabalho que gostaria de desenvolver na prático. Resumidamente, decidiram que todos trabalhariam na comunidade, onde fariam estudos a respeito de:

- exame parasitológico de fezes: $100 \%$

- trabalho voltado para educação em saúde: $85,71 \%$

- levantamento de condições sócio-econômica-cultural-sanitárias: $71,43 \%$

- o tratamento das pessoas parasitadas: $57,14 \%$

- um trabalho num bairro periférico: $14,29 \%$

- uma campanha de esclarecimento junto à população sobre saúde: $14,29 \%$

- levantamento e estudo de doenças relacionadas ao saneamento num hospital-escola local: 14,29\%

- visita domiciliária às famílias: 14,29\% 
Dessa exposição e discussão dos GE, foram selecionadas as seguintes idéias que serviram de base para o planejamento do trabalho prâtico:

- Essas atividades seriam desenvolvidas num Parque Infantil de um bairro periférico da cidade de Ribeirão Preto.

- Nesse parque seriam programadas: aulas sobre higiene verminose a grupos de crianças formados segundo a idade; exame parasitológico de fezes de todos os matriculados; tratamento dos parasitados; seleção de algumas famílias dessas crianças para serem visitadas e obter dados de condições sócio-econômico-cultural-sanitárias das mesmas.

Firmadas estas bases o trabalho de campo, os próprios alunos da EERP-USP dividiram-se em 6 (seis) grupos. Cada grupo elegeu seu coordenador e a classe escolheu um coordenador geral para esta segunda fase dos trabalhos.

a) Divisão dessas atividades para execução de trabalho de campo.

Para tanto, os grupos receberam as seguintes tarefas assim distribuídas:

GRUPO I - Planejamento: montar o plano de trabalho, baseado nas idéias que foram expostas pela classe. Apresentá-lo para discussão e submetê-lo à aprovação da mesma.

GRUPO II - Questionário: elaborar um questionário para levantamento sócio-econômico e sanitário e apresentá-lo para discussão e aprovação.

Providenciar, depois, material suficiente para toda classe simular uma aplicação antes de aplicá-lo no campo.

GRUPO III - Levantamento de dados: alistar todas as crianças matriculadas no Parque Infantil, colocando: nome, sexo, idade, cor e residência.

Efetuar um sorteio de 64 (sessenta e quatro) dessas crianças, para serem visitadas para o preenchimento do questionário sócioeconômico-sanitário.

Distribuir as crianças sorteadas, com os nomes e endereços, para que cada aluno da EERP-USP pudesse fazer no mínimo uma visita e aplicar um questionário.

GRUPO IV - Material e medicamento - entrar em entendimento com o Centro de Saúde e Serviço de Enfermagem de Saúde Pública do Hospital das Clínicas de Ribeirão Preto para providenciar: miaterial para colheita de fezes (latinhas, espátulas, fita gomada) e medicamentos para tratamento dos parasitados.

Levar ao conhecímento do médico do Parque Infantil, o trabalho planejado e pedir sua colaboração (principalmente quanto às prescrições) . 
GRUPO V - Parte educativa: Montar planos de aulas a serem chadas acs alunos, de acordo com os seguintes grupos etários:

1..$^{\circ}$ grupo: de 3 a 6 anos

2. grupo: de 7 a 8 anos

3..$^{\circ}$ grupo: de 9 a 12 anos

Esta divisão foi baseada em situação escolar da criança, isto é, os pré-escolares, os que estão frequentando o primeiro ano, e os já alfabetizados. A finalidade desta classificação foi permitir a elaboração de planos de aulas adaptados a cada grupo etário.

Após a elaboração, expor à classe para discussão e aprovação.

GRUPO VI - Exame de fezes: entrar em entendimentos com o laboratório do Departamento de Parasitologia da FMRP - USP*, para organização de um calendário de entrega do material.

No Parque: anotar o rúmero total de exames a serem feitos e distribuí-los pelos dias que deverão ser encaminhados. Providenciar o encaminhamento diário do material, no período da manhã para o laboratório.

Receber os resultados e anotá-los nas listas previamente preparadas, por classe. Manter contactos freqüentes com o Parque (informando-se sobre o encaminhamento que está sendo feito); com o Laboratório (como está chegando o material e recolher os resultados) e contacto com o grupo responsável pelo material e medicamento, para anotar dados e providenciar medicamentos.

b) Descrição da área escolhida

O Bairro de Vila Lobato está localizado na periferia da cidade de Ribeirão Preto. Possui poucas ruas, sem guias e com vegetação invadindo as mesmas. As casas são feitas de alvenaria, ou madeira, havendo alguns barracos improvisados.

Há rede de luz elétrica no bairro, mas, há casas que ainda usam lamparinas a querosene.

O abastecimento de água é feito: uma parte pela rede pública (mas nem todas as casas possuem torneiras dentro de casa), outras por poço raso e outras por uma fonte.

Quanto ao destino dos dejetos: uma parte do bairro utiliza o sistema público de esgoto, a maior parte serve-se de fossa seca e negra, e o restante usa curso de água ou deposição na superfície do solo. As instalações sanitária, na sua maioria, estão localizadas fora die casa.

Os quintais são secos, ensolarados e bem ventilados.

Há criação de animais domésticos, soltos pelo quintal.

Apenas algumas residências são beneficiadas pela coleta do lixo

* F.M.R.P. - USP - Faculdade de Medicina de Ribeirão Preto da Universidade de São Paulo. 
municipal. Observa-se que a maioria deixa-o no quintal enquanto alguns queimam ou enterram-no.

c) Parque Infantil

Está localizado no próprio, com a denominação de Parque Infantil de Vila Lobato. Ocupa uma área de aproximadamente $2550 \mathrm{~m}^{2}$ com salas de aula, salas para administração, médico e enfermagem, sanitários e chuveiros para ambos os sexos. Possui um galpão coberto, onde as crianças fazem recreação e recebem alimentos. Anexo a ele a despensa e a cozinha para preparo e armazenamento de alimentos.

À volta de tcdo prédio, há uma área gramada, destinada a recreação, tendo um "play-ground" e uma horta, o que permite livre circulação das crianças.

O parque recebe crianças de 3 (três) a 12 (doze) anos de idade. Na época de nosso trabalho, a matrícula era de 375 crianças. A manutenção é feita pela Prefeitura Municipal de Ribeirão Preto.

O sistema de permanência das crianças é do período integral. As crianças recebem refeições no próprio recinto. As que se encontram fazendo curso primário saem para ir ao grupo, que fica no próprio bairro, voltando para o parque no final do período escolar que frequentam.

Os pré-escolares ficam todo o período no estabelecimento, em atividades (geralmente recreativas), supervisionadas por professores.

Deve-se a escolha deste Bairro e Parque, primeiro ao fato de o local satisfazer os requisitos para a execução do plano e segundo por possuir médico, o que permite a Instituição a continuidade do trabalho, mesmo depois da saída dos alunos de enfermagem.

Foi montado um calendário, especificando dia, hora, local, atividade e responsáveis, para não nos perdermos na execução.

I icou estabelecido que cada aluno da EERP deveria dar sua aula para as crianças e assistir a uma de um colega e realizar duas visitas domiciliares. aplicando o questionário.

Seriam dadas 8 (oito) aulas por dia, distribuídas de tal forma, que em 4 (quatro) dias, todos os alunos da EERP já teriam dado suas aulas e todas as crianças assistido às mesmas.

As visitas às famílias das crianças sorteadas seriam realizadas em um só cia, ficando para uma outra data visitas àquelas não localizadas ou ausentes do domicílio nesse dia.

O plano foi executado com algumas alterações por causa das dificuldades inerentes a este tipo de trabalho, porquanto, de alguns exames de laboratório ainda não tínhamos os resultados e algumas crianças ainda não haviam enviado os seus. Os medicamentos foram providenciados, calculando-se o suficiente para cobrir os parasitados, além de vitaminas, sais minerais e ferro que, embora não constassem do plano, os alunos providenciaram. 


\section{III - FINAL DA PRIMEIRA PARTE}

Nesta fase os grupos se desfizeram e a classe passou a trabalhar como um único grupo, coordenado pela aluna por eles eleita para esse cargo, e sob a supervisão da professora de saneamento.

Os dados do levantamento sócio-econômico-cultural e sanitário e os resultados dos exames parasitológicos de fezes, passaram a ser revistos, estudados, analisados, passados para gráficos e tabelas, discutidos e elaborada uma conclusão.

Marcada data e local, foi uma apresentação de todo o trabalho, com a presença de toda a classe, dos professores de parasitologia, scciologia, estatística, saneamento e outros profissionais de saúde, que foram convidados pelos alunos.

A apresentadora foi um elemento escolhido pela classe, que usou gráficos, tabelas e citações de livros-textos para melhor ilustrar e apoiar o trabalho.

No final, foi dada a palavra aos presentes, que fizeram comentários realçando alguns pontos, relembrando outros que precisariam ser mais cuidados e complementando outros.

Os alunos entregaram nesta ocasião um relatório de todo o trabalho realizado.

\section{IV - APRECIAÇÃO, CRÍTICA E SUGESTÕES DOS ALUNOS; QUANTO À METODOLOGIA EMPREGADA}

Foi pedido aos alunos que respondessem a um questionário, cujas respostas serviriam como medida de avaliação da metodologia empregada e serviria de fonte de informação para futuras programaçōes. Não necessitaria ser identificado.

As respostas obtidas, procuramos classificar em: Positivas*, Negativas** e Neutras***, sendo o resultado expresso em percentagem.

O questionário constou de duas partes:

A - avaliação da parte teórica

B - avaliação da parte prática

Para garantia da fidelidade da expressão usada pelos alunos, procuramos repetí-la como nos foi dada, em seguida à pergunta.

\footnotetext{
* - Positiva - acharam a metodologia usada eficiente, valorizando a disciplina.

** - Negativa - Não acharam a metodologia usada eficiente, não valorizando a disciplina.

**** - Neutra - Não se definiram, ou não responderam.
} 
PARTE A - AVALIAÇÃO DA PARTE TEÓRICA

1 - COMO VOCÊ SE SENTIU AO TOMAR CONHECIMENTO DOS TÓPICOS QUE. ESTUDARIA EM SANEAMENTO?

- A essa pergunta $50,00 \%$ dos alunos disseram ser a matéria importante, declarando alguns ser a oportunidade um privilégio; interessante, bom, importarite, útil para a carreira de enfermagem, muito entusiasmo; $37,50 \%$ incluíram respostas do tipo: essa matéria não lhe causou sensação, não deu importância; pensou que seria "chato", achou que tais assuntos não eram para serem dados numa Faculdade; que não tinha importância a ponto de ser dado um curso; assunto sem grancle importância; se sentiu frustrada; descontente. O restante, $12,50 \%$, não se definiu pois umas ficaram surpresas, outras tiveram a expectativa e ansiedade natural do início c cutras acharam a matéria comum.

\section{2 - CCMO SE SENTIU COMO ELEMENTO DE UM GRUPO PARA ESTUDO E FREPARO DE SIMPÓSIO?}

- Em resumo $84,38 \%$ dos participantes disseram que se sentiram bem, acharam a experiência boa, um trabalho ótimo; $9,38 \%$ não gostaram ou por não terem facilidade para esse tipo de trabalho ou por não se darem bem com algum elemento do grupo; $6,25 \%$ não se definiram.

\section{3 - VOCÊ GOSTARIA DE TER FICADO COM OUTRO ASSUNTC PARA ESTUDO? QUAL?}

- 75,60\% dos alunos disseram que não gostariam de ter ficado com outro assunto (alguns acharam que foram privilegiados, enquanto que outros acharam o seu assunto mais importante); outros, $15,63 \%$, disseram que gostariam de estudar outro assunto, uns por acharem "excreta" assunto pouco agradável e outros por preferirem outros assuntos como: lixo, esgoto e alimentos, enquanto $9,38 \%$ cisseram que gostariam de participar de todos além dos seus.

\section{4: - COMO SEN'TIU SUA APRESENTAÇÃO? E A DE SEU GRUPO?}

4.1 - No aspecto individual, $78,13 \%$ dos alunos acharam que foi uma experiência proveitosa, positiva e importante para o desembaraço do aluno diminuindo a inibição, proporcionando amadurecimento; os demais $12,50 \%$ assim se manifestaram: sentiram-se nervosos, um achou que não deu certo, que foi muito teórico na aresentação e outro achou uma péssima experiência; 9,37\% destes 
últimos disseram não saber avaliar, não acharam nada de excepcional na experiência; outro achou que foi "mais ou menos".

4.2 - No aspecto grupal, $87,50 \%$ dos elementos sentiram que a apresentação do grupo deu-se num ambiente favorável, trazendo boa contribuição para a classe, com muitos aspectos positivos, enfim foi uma experiência necessário; entretanto, $12,50 \%$ acharam que seu grupo estava indeciso, excessivamente teórico, que a classe prestou pouca atenção alguns elementos trabalhado pouco.

5 - QUE APRESENTAÇÃO CLASSIFICA COMO MAIS EFICIENTE? (NA FORMA E NO CONTEÚDO).

- A Classe classificou:

\begin{tabular}{|c|c|}
\hline LUGAR & ASSUNTO \\
\hline 1.0 & Dejetos e lixo \\
\hline $2 .^{\circ} \ldots$ & Água e alimentos \\
\hline
\end{tabular}

B - DOS ASSUNTOS ESTUDADOS, QUAIS OS QUE VOCÊ ACHA QUE SERÃO OS MAIS UTILIZADOS NA SUA ATUAÇÃO COMO ENFERMEIRO? (COLOQUE POR ORDEM DE IMPORTÂNCIA)

Esta pergunta foi respondida, colocando-se os assuntos em ordem de importância, o que nos mostra o quadro abaixo:

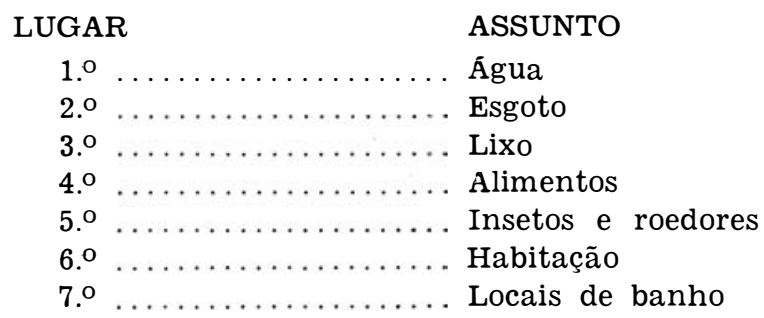

7 - COMO ESTUDANTE DE ENFERMAGEM, QUAIS AS CONTRIBUIÇÕES QUE A TEORIA DO SANEAMENTO LHE TROUXE?

A essa pergunta $20,63 \%$ dos alunos responderam que foi uma contribuição útil, não só para a vida profissional, como de aplicação diária em nossa vida e da coletividade. Acrescentaram que deu uma visão de relação entre saneamento e doenças, mostrando os contactos e as pessoas com os quais teremos relacionamento no campo de saúde pública. Possibilitar o desenvolvimento e adestramento nas técnicas, evidenciando a importância de campanhas de educação e 
promoção junto à comunidade. Aguçou a observação e ensinou desenvolver improvisação. Os demais $9,3.7 \%$ nada responderam.

\section{$\varepsilon$ - QUE SUGESTÕES VOCÊ DÁ À PROFESSORA QUANTO À FORMA DE PLANEJAMENTO DE EXECUÇÃO DA PARTE TEÓRICA PARA MELHORIAS FUTURAS?}

- Dos 32 alunos, $18,75 \%$ não responderam, e $81,25 \%$ responderam que gostaram do curso, acharam a forma e o conteúdo bons, mas não deram sugestões; enquanto os demais, isto é, 40,62\% (13 alunos) assim se expressaram: Dois acharam que o curso deverá ter mais horas com mais tempo para as atividades, outros dois acharam que as visitas deverão ser feitas com toda a classe; outros dois sugeriram que os alunos sejam mais motivados para a apresentaçāo de seu seminário, inclusive revendo o trabalho antes da apresentação; ^ professora dar mais aulas a fim de permitir que a classe converse mais com a professora, aproveitando mais sua experiência, foi a sugestão de outros dos alunos; apostilar para comentar posteriores foi sugestão dada por mais três alunos; intercalar seminário com aula da professora, foi outra sugestão e ainda, modificar o conteúdo de um ano para outro evitando cópia de trabalhos, foi também sugestão dada por um aluno.

\section{PARTE B - AVALIAÇÃO DA PARTE PRÁTICA}

\section{1 - QUAL FOI SUA PARTICIPAÇÃO NA FASE DE DISCUSSÃO E PLANEJAMENTO DO TRABALHO DE CAMPO? EXPLIQUE?}

- A resposta obtida de $68,75 \%$ dos alunos foi: sentiram que participaram ativamente, trabalharam muito, sentiram a união do grupo, o ambiente era de colaboração, "foi um trabalho de que sempre quis participar", sendo a primeira experiência como enfermeiros; outros, $15,63 \%$ disseram não ter participado no início pois só aceitaram sugestão, não emitindo opinião; os 15,63\% restantes não se definiram.

\section{2 - A QUE GRUPO VOCÊ PERTENCEU NO TRABALHO PRÁTICO E COMO SE SENTIU DURANTE O DESENVOLVIMENTO DO TRABALHO?}

- Os 32 alunos mencionaram a que grupo perteceram, e $62,50 \%$ afirmaram gostar do trabalho, acharam-no interessante e produtivo, sentiram-se à vontade; embora com algumas dificuldades, estavam animados, achando que foi fácil vencê-las; um grupo que compreendia $25,00 \%$ dos alunos se manifestou: um disse que não foi pro- 
veitoso; outro atribuiu esse resultado à falta de dados e colaboração restrita de alguns elementos da área de saúde, outro se sentiu sem condições físicas; outro declarou que não estava certo dos objetivos; cutro não gostou porque teve que coordenar a classe e outro ainda disse que "não achou empreendedor". Cerca de $12,50 \%$ não se definiram, pois nada responderam.

A maior frequência de respostas negativas num total de quatro (4), isto é, $12,50 \%$ foi do grupo de levantamento de dados, sendo que quatro (4) alunos se manifestaram alegando: dificuldades de trabalho de campo; sobrecarga no início (depois acalmou); senti-me um pouco inútil pela falta de condiçōes físicas"; "no início me senti ciesanimada pela falta de coloboração de alguns profissionais do setor de saúde".

3 -- GUSTARIA DE TER PERTENCIDO A OUTRO GRUPO? QUAL?

- A esta pergunta, $56,25 \%$ dos alunos disseram ter-se sentido integrados ao grupo e na atividade, portanto, não queriam mudanças. Outros $37,50 \%$ gostariam de pertencer a outro grupo e o mais indicado foi para o exame de fezes. Finalmente $6,25 \%$ não se definiram.

\section{4 - QUE CONTRIBUIÇÃO LHE TROUXE O CONTACTO COM AS FAMÍLIAS DAS CRIANÇAS? POR QUE?}

- Para um grupo de $75,00 \%$ o trabalho foi positivo e disseram que permitiu relacionar o estado de saúde das crianças e o ambiente doméstico, observar tradições existentes, conhecer a periferia e suas r:ecessidades reais, perceber o trabalho que precisa ser feito junto a essas famílias e o quanto elas precisam do pessoal de enfermagem. "Vimos coisas que não pensávamos existir, com isso aprendemos a valorizar o que temos, a pensar nos outros e a necessidade de campanhas contínuas".

Das restantes, $9,3.8 \%$ acharam em vão o que estavam fazendo, que o contacto foi pequeno, não viram nada de relevante tendo uma achado o trabalho muito nocivo; enquanto $15,62 \%$ nada responderam, pois incluia-se aí duas que não fizeram visitas.

\section{5 - ATUANDO COMO EDUCADORA JUNTO A ESCOLARES, COMO LHE PARECEU ESTA FUNÇÃO?}

- Num grupo de $84,38 \%$, encontramos respostas assim descritas: acharam esta função muito importante, sendo a melhor parte do trabalho. Embora difícil, árdua foi positiva, pois nesta atividade $\dot{e}$ que estaremos preparando as melhorias futuras. Muita responsa- 
bilidade, porém, muito honrosa e necessária. A enfermeira tem condições de ser uma educadora e está perfeitamente ajustada nessa função. Achei que "é semente" que germina na certa. Outra fração, $6,25 \%$ disse que sinceramente não gostaria de fazer isso por não se dar bem como educadora. Das três restantes, $9,38 \%$, duas não responderam e outra achou que uma experiência a mais no campo da saúde.

\section{8 - ACHA QUE O TRABALHO PRÁTICO LHE TROUXE ALGUMA CONTRIBUIÇÃO QUE PODE ENUMERAR? QUAL?}

- Dos que responderam afirmando positivamente, isto é, 96,88\%, podemos assim enumerar:

- foi uma experiência em saúde pública que proporcionou maior união da classe;

- pudemos fazer uso dos conhecimentos de didática e estatística;

- oportunidade de conhecer uma área e uma situação não conhecidas;

- vimos a impcrtância dos aspectos educativo e preventivo;

- pusemos em prática a teoria estudada;

-- tivemos contacto direto com as crianças através das aulas;

- mantivemos contacto com pais e familiares no qual eles puderam sentir nosso interesse;

- permitiu-nos uma análise da influência ambiental;

- foi um "pilotinho" para o futuro, onde sentimos as facilidades e dificuldades, conhecendo o campo de nossa profissionalização.

Somente uma fração de $3,13 \%$ não respondeu.

7 - COMO ESTUDANTE DE ENFERMAGEM, O QUE O SANEAMENTO TROUXE DE CONTRIBUIÇÃO NA PARTE PRÁTICA?

- Dos 32 (trinta e dois) alunos, $93,75 \%$ disseram que o saneaniento contribuiu dando-lnes experiência em planejar e executar um trabalho, facilitando-lhes tarefas futuras. Foi uma aplicação da teoria dando uma visão bem real do nosso futuro campo de ação na área de saúde pública; mostrou-nos o número de parasitados de uma região e pudemos sentir o que é "praticar", diminuindo nossa timidez e inibição. Sentimos que este aprendizado será usado em saúde pública ,no hospital e no cotidiano. "É tão importante que fiz minha mãe ler as apostilas e colocar todos os ensinamentos em prática, além de os transmitir para o resto da família”.

Apenas 6,25\% (isto é, dois alunos) não responderam. 
8 - PARA VOCÊ O SANEAMENTO BÁSICO TEM RELAÇÃO COM O APARECIMENTO DE DOENÇAS? QUAIS? PODE EXEMPLIFICAR?

- A totalidade da classe, isto é $100 \%$ disse que sim, citando como exemplo, as verminoses, as doenças parasitárias, as doenças infecciosas e principalmente as diarréias.

\section{9 - EXISTE PONTO DE LIGAÇÃO ENTRE: SANEAMENTO E PARASITOLOGIA?}

- A totalidade da classe, $100 \%$, disse que sim, lembrando os problemas das doenças parasitárias e as relações com o meio ambiente.

\section{SANEAMENTO E ESTATÍSTICA?}

- Toda a classe, $160 \%$, foi unânime em afirmar que há ligações e as razões apontadas foram: ajuda na coleta, tabulação, análise, comparação de dados e elaboração de tabelas; permite "ver" as as causas das doenças que mais ocorrem numa região; permite melhor exposição de dados; facilita o arquivo dos mesmos para estudos presentes e futuros; através dela conseguimos verificar a situação de saúde que queremos estudar; averiguar e aplicar recursos em áreas de maior incidência. Sem a estatística não haveria razão de ser os trabalhos de pesquisa. Os dados estatísticos premitem, ainda, mostrar condições para compará-las com outras regiōes e, na própria região, após campanhas.

\section{SANEAMENTO E SOCIOLOGIA?}

- Quase toda a classe, $96,88 \%$ dos alunos anotaram ligações as 2 (duas) disciplinas, afirmando através delas conseguimos a compreensão de problemas sociais da classe mais baixa, os hábitos e reaçōes das pessoas ligadas a crenças e tradições e o relacionamento com as pessoas compreendendo seus modos, costumes e padrões de vida. Mostrou-nos fatores sócio-econômico-educacionais das famílias e relações com doenças. Permitiu tratar as pessoas de acordo com "seus" valores e não com os "nossos", ver os fatos como são e não como gostariamos que fossem. Entendendo o homem, seu comportamento, crenças, condiçōes psico-sociais, poderemos ter melhores elementos para a solução de problemas de saneamento, pois a dimensão das medidas de saneamento é dada pelas condições sociais. 


\section{SANEAMENTO E ENFERMAGEM}

- Todos os alunos, $100 \%$ disseram existir ligações entre ambos, pois o saneamento está contido na enfermagem, caminham juntos e são fundamentais. É muito importante e é básico para o aluno e enfermeiro; sem o saneamento não existiria a enfermagem. Sua importância já está evidenciada pelo fato de existir como disciplina num curso de enfermagem e ligado à saúde pública. O próprio objetivo do saneamento está incluído na definição de enfermagem.

Para que existir enfermagem sem saneamento?

\section{0 - COMO FOI A VISITA QUANTO À ABORDAGEM E RECEPÇÃO? TEVE DIFICULDADES? QUAIS?}

- Dos 32 alunos, 30 fizeram visitas domiciliares porque dois não conseguiram localizar o endereço que lhes foi dado: Dos que fizeram $90,32 \%$ assim se manifestaram sobre a recepção e abordagem: fomos muito bem recebidos e não tivemos dificuldade na abordagem, enquanto $9,67 \%$ sentiram-se tímidos e receosos na primeira visita e mais à vontade e melhor na outra.

A maior dificuldade, que foi lembrada por $23,33 \%$, foi a localização do domicílio, enquanto dois alunos, isto é, 6,67\% sentiram dificuldade quando o visitado começou a lamentar e, outra aluna, na forma de interromper a narração da pessoa acerca de sua doença.

\section{1 - O QUE VOCÊ ACHOU DE.STA ATIVIDADE?}

- Dos trinta alunos que fizeram visitas $46,67 \%$ gostaram da atividade, dizendo ser uma oportunidade de conhecer a população, ver coisa e situações novas, conhecer pessoas diferentes. Foi melhor do que esperávamos. Mostrou-nos essa experiência que muitas famílias têm conhecimento, mas não têm recursos para pô-lo em prática, e os problemas são muitos para serem resolvidos a curto prazo. Senti-me útil transmitindo conhecimento não esperava que a visita e aplicação do questionário fosse tão agradável. Achamos que as visitas deveriam ser mais frequentes, que poderíamos obter mais dados e, uma vez obtidos os resultados dos exames de fezes, deveríamos levá-los para as famílias, pois elas ficam na expectativa de vê-los. Nota-se que as visitas satisfazem a necessidade daquelas pessoas de se comunicarem.

Os demais alunos, $53,32 \%$, nada disseram.

(A média de tempo gasto para cada visita foi de 16,16 minutos). 
12 - DURANTE A AULA, OS ALUNOS ESTAVAM INTERESSADOS? QUE TIPOS DE PERGUNTAS APARECERAM? A AULA FOI DADA DE ACORDO COM O PLANO? COMO VOCÊ SE SENTIU DURANTE A AULA? FEZ A VERIFICAÇÃO DA APRENDIZAGEM?

- Toda classe planejou e preparou o material com antecedência, 31 (trinta e um) deram aula, desses, $46,88 \%$ tiveram que alterar o plano na hora e $53,12 \%$ deram de acordo com o planejado.

Dos que deram aula, $83,87 \%$ sentiram-se à vontade e sem dificuldades e $16,13 \%$ sentiram-se inibidos principalmente no início.

\section{3 - QUAIS SÃO SUAS CRÍTICAS E SUGESTÕES PARA TODO O NOSSO CURSO?}

- Mais de três quartos dos alunos $78,13 \%$ acharam que o curso foi ótimo, interessante, bom, planejado, motivou o aluno, deu possibilidade aos alunos de trabalharem mais e foi bom pela característica pessoal do professor. A parte prática foi muito melhor que a teórica. Atingimos nossos objetivos. Entretanto, menos de um quarto cos alunos, $21,88 \%$, não se manifestaram.

CRÍTICAS - Apenas $15,65 \%$ da classe apresentou suas críticas que podem ser assim enumeradas individualmente:

- tempo curto para realizar o trabalho;

- teoria foi um pouco monótona;

- houve acomodação de alguns alunos;

- faltou colaboração de alguns setores e sobrecarga para alguns grupos.

SUGESTÕES - de toda a classe, $12,50 \%$ apenas deram as seguintes:

- dar mais tempo para o trabalho prático;

- se não fosse difícil, todo o curso deveria ser dado desta forma:

- apresentar o trabalho no início do curso (1. ${ }^{\mathrm{a}}$ ou $2 .^{\mathrm{a}}$ aula) $\mathrm{e}$ dizer como serão os questionários, gráficos e tabelas;

- estou de acordo que o curso continue assim, pois é o aluno que tem de pesquisar, ler e procurar;

- acho que a própria professora deve coordenar o grupo, pois assim, haverá incentivo maior e intercalar simpósio e aulas do professor.

De uma forma geral, os alunos da EERP disseram que lhes chamou atenção o fato de algumas crianças já terem noções sobre os assuntos e o interesse das mesmas em aprender; a vivacidade, a participação e boa vontade por elas demonstradas. Alguns ficaram curiosos para saber por que não devem nadar em lagoas; outros 
queriam saber sobre os "bichos da barriga", se os mesmos tem rabo, cabeças, como entram na barriga e como são tirados. Outros ficaram interessados no material audio-visual usado (cartazes bem coloridos, figuras, desenhos e material para ser desenhado e pintado na hora).

Houve oportunidade de $83,87 \%$ fazerem varificação do aprendizado. Alguns fizeram no dia e outros em datas posteriores, obserrando que na maioria houve sinais de mudança como unhas limpas c. cabelo arrumado.

\section{$V$ - DISCUSSÃO}

Ouvir os alunos da EERP, acerca de uma metodologia é sempre interessante, pois o que montamos, atendendo a objetivos fixados para um determinado ano de curso, nem sempre chega aos alunos da forma que esperamos.

Nesta programação para a disciplina de saneamento, fizemos um esforço em seguir um caminho que nos permitisse sair das salas de aula, para irmos à comunidade, ver nossa periferia e lá observar: a situação de saneamento, como vive a população, o que ocorre com as crianças que nela vivem.

Por outro lado, achamos que seria de maior eficiência para alunos, professores, e a própria comunidade, trabalhar com outras aisciplinas, dando aos alunos uma oportunidade de integrar e aplicar conhecimentos, ao mesmo tempo em que o aprendizado seria reforçado com maior frequência e intensidade. Foi esta a razão que nos levou a programar o curso com as disciplinas de sociologia, parasitologia e estatística.

Pelos resultados do inquérito aplicado aos alunos, vê-se que a maicria fez esse relacionamento, mostrando e exemplificando relações entre essas disciplinas e o saneamento.

Notamos durante a realização da parte prática, que os professnres foram procurados, principalmente o de parasitologia e estatística, na busca de esclarecimentos e discussões dos resultados.

Os resultados dos exames parasitológicos de fezes, são perfeitamente coerentes com a situação do meio, e nada de novo revelam, mas o aluno que ingressa num curso superior, que vê em seu currículo inúmeras disciplinas, precisa ter a oportunidade de ver como estas se completam e interligam, como nós as usamos na prática e a comprovação da teoria estudada. Os alunos nos mostraram que há no início uma certa resistência ou preconceito com a disciplina saneamento, que vai desaparecendo no decorrer do curso e sendo substituído pelo entusiasmo, à medida que passam a observar e analisar a influência do meio físico sobre o homem, chegando às suas próprias conclusões. 
O trabalho em grupo, que achamos ser o mais coerente para essa situação, foi aceito. apenas com uma restrição, que os grupos fossem formados não de forma aleatória (como foi na parte A), mas pela própria escolha deles. No entanto a maioria concordou que o trabalho em grupo foi proveitoso, sentiram-se valorizados por darem aceitas suas sugestões e proporcionou maior união entre eles, como era de se esperar. Criticaram também dizendo haver "elementos que não assumiram sua responsabilidade" e "alguns que se acomodaram".

O trabalho em grupo, e na comunidade, foi uma intensão nossa, por saber que, uma vez habilitados, trabalharão como elementos de uma equipe de saúde.A oportunidade houve. Trabalharam junto a médicos, enfermeiras, técnicos de laboratório, atendentes e outros profissionais que não sendo da área de saúde, colaboraram com essas a.tividades. No entanto, foi criticada a falta de colaboração de alguns profissionais e de alguns setores, o que, segundo os alunos, trouxe dificuldades. Para nós, isīo também foi bom, por ser um aprendizado que é coerente com a realidade. Tiveram que improvisar, tomar decisōes, alterar planos para continuarem o trabalho. Isto trouxe para. eles uma sobrecarga maior, no entanto mostrou que souberam resolver a situação criada.

Na parte prática, não há dúvidas que houve um grupo (de exame de fezes), que ficou sobrecarregado em atividades e foi na realidade um dos mais produtivos, pois, mesmo depois de entregue o relatório final, seus participantes continuaram a enviar material e anotar resultados. Apesar disso, quando se perguntou à classe se gostaria de pertencer a outro grupo de trabalho prático, a maior porcentagem disse que gostaria de ter ficado no grupo de "Exame de fezes", pois trabalharia mais.

Houve alguns alunos que se chocaram com a realidade periférica da cidade, pois segundo, eles não sabiam existir situações com aquelas.

Apesar das dificuldades, não houve desânimo. Os alunos da EERP fizeram visitas domiciliárias, sob uma forte chuva, no €ntanto, a maior dificuldade apontada por $23,33 \%$ foi a de localizar o domicílio no endereço fornecido.

Uma aluna chegou a declarar que enfermagem de saúde pública rão será sua opção; por outro lado, outras viram que é conhecendo a situação que poderemos programar de acordo com a realidade. Dissram: "Vimos o que não pensávamos existir aprendendo com iss a valorizar o que temos, aprendemos a pensar nos outros e percebemos a necessidade de campanhas frequentes".

Uma pergunta que a classe nos fez no planejamento do trabalho de campo foi:

- O nosso trabalho terá continuidade? 
Para responder a esta pergunta, trouxemos a enfermagem estagiária do parque para uma de nossas reuniōes e falamos com o médico responsável. A resposta de ambos foi: sim.

Achamos que o caminho seguido proporcionou ao aluno a vivência de papéis e funçōes que os aguardam como enfermeiro. Viram um pouco da comunidade, conheceram crianças pré-escolares, e escolares, viveram algumas horas dentro do ambiente de um Parque Infantil, visitaram famílias, viram o ambiente físico, ensinaram, orientaram, confrontaram diferentes resultados de exames parasitológicos de fezes, dialogaram com professores, estiveram em várias instituiçōes da cidade (indústrias cooperativas, departamento da Prefeitura de Ribeirão Preto, clubes, BNH, escolas, Centro de Saúde, Departamento de Parasitologia e Microbiologia da FMRP), marcaram visitas, enviaram ofícios, fizeram entrevistas, requisitaram material e condução. Assim viveram uma situação que exigiram tomada de decisões, o que, a nosso ver, desperta nos alunos responsabilidades e a aquisição de maturidade e isto faz com que se sintam elementos úteis, capazes de realizar uma tarefa em seu seu campo profissional. Usando as palavras da própria classe: "foi uma possibilidade de o aluno trabalhar mais, com união maior da classe, de forma mais ativa e uma contribuição útil, não só como de aplicação diária em nossa vida e da coletividade.

\section{VI - CONCLUSÃO}

A metologia empregada, proporcionou ao aluno a saída das salas de aula, par irem à comunidade e suas instituições, observando e anotando condições ligadas às teorias estudadas e ao mesmo tempo integrando e relacionando conhecimentos adquiridos em outras disciplinas, foi avaliada pela própria classe, dando-nos elementos, que nos permitem as seguintes conclusōes:

1. Os alunos têm incialmente preconceito em relação ao estudo de saneamento.

2. A técnica de grupo mostrou-se bom meio para este ensino, mas os grupos deverão ser formados pela própria classe.

3. Embora a dinâmica na apresentação de uma assunto possa influir na melhor compreensão do mesmo, não interfere na classificação desses assuntos quanto a sua utilidade prática.

4. A técnica permitiu concluir unânimente que o saneamento tem relação com o aperfeiçoamento de doenças, principalmente as infecto-contagiosas e parasitárias.

5. A parte prática permitiu aos alunos viverem a experiência de montar, executar, analisar e discutir os resultados de um trabalho, executando no campo a teoria aprendida nas salas de aula, cientro de um plano por eles escolhido e montado. 
6. A metodologia adotada permite relacionar conhecimen'ios de cutras disciplinas tanto na teoria como na prática. Esse valor foi mostrado em relação às disciplinas de estatística, sociologia, parasitologia e saneamento.

7. Este trabalho didático foi uma oportunidade que tivemos de integrar uma experiência de ensino à prestação de serviço à comunidade.

\section{AVALIAÇÃO QUANTO AO CURSO}

Estas observações são importante para avaliação do próprio programa e para programações futuras.

\section{PARTE A}

1. Como você se sentiu ao tomar conhecimento dos tópicos que estudaria em Saneamento?

2. Como se sentiu como elemento de um grupo para estudo e preparo dos seminários?

3. Você gostaria de ter ficado com outro assunto? Qual?

4. Como se sentiu sua apresentação? E a do seu grupo? (o que trouxe de contribuição para você mesma, em pontos negativos e positivos?)

5. Qual a apresentação voce classificaria como mais eficiente, na forma e no conteúdo? 
6. Dos assuntos estudados quais os que você acha que serão mais utilizados na sua atuação como enfermeiro? (coloque por ordem de importância).

7. Como estudante de enfermagem, quais as contribuições que a. teoria do Saneamento lhe trouxe?

8. Que sugestões você dá à professora quanto à forma de planejamento e execução da parte teórica, para melhorias futuras?

\section{PARTE B - PARTE PRÁTICA}

1. Qual foi sua participação na fase de discussão e planejamento do trabalho de Campo? Explique.

2. A que grupo você pertenceu no trabalho prático, e como se sentiu durante o desenvolvimento do trabalho?

3. Gostaria de terpertencido a outro grupo? Qual?

4. Que contribuição lhe trouxe o contato com as famílias das crianças do trabalho? Por quê? 
j Atuando como educadora junto a escolares, como lhe pareceu esta função?

6. Acha que o trabalho prático trouxe alguma contribuição que você pode enumerar? Quais?

7. Como estudante de enfermagem, o que o saneamento trouxe de contribuição na parte prática?

8. Para você, o saneamento básico tem relação com aparecimento de doença? Quais? Pode exemplificar?

\&. Existem pontos de ligação entre:

Saneamento e Parasitologia?

Saneamento e Estatística?

Saneamento e Sociologia? Quais?

Saneamento e Enfermagem?

1C. Quais são suas críticas e sugestões para todo o nosso curso?

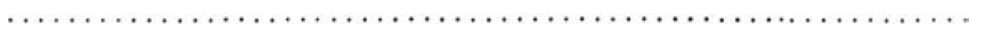

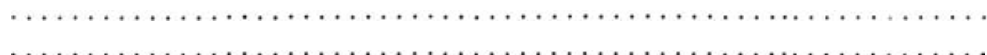

